\title{
Getting places in New Zealand neighbourhoods
}

\author{
K. Witten \\ Centre for Social and Health Outcomes Research and Evaluation, \\ Massey University, New Zealand
}

\begin{abstract}
Health outcomes vary between neighbourhoods. Research on the determinants of this variation has shown that the characteristics of places matter as well as the characteristics of people living in places. Differing levels of access to services and amenities, such as parks and recreational facilities, education and health care facilities have been identified as a possible explanation for neighbourhood differences in health. Transport is about getting to places, a crucial aspect of accessibility.

The paper describes the relationship between community resource access and deprivation in New Zealand neighbourhoods and discusses the impact of transport availability on the lives of people living in neighbourhoods with varying levels of deprivation and service and amenity access.

Locational access to 16 types of community resources was mapped using GIS for all small area units (neighbourhoods) across urban and rural New Zealand. In a more in-depth analysis within two cities in the Auckland region, access to 36 types of services and amenities was mapped and a composite Community Resource Accessibility Index developed. A consistent finding of both studies has been a significant positive relationship between deprivation and access to services and amenities: poorer neighbourhoods generally have better access. However pockets of poor access in higher deprivation areas were identified. Qualitative investigations in neighbourhoods with poor access reveal the impact that limited transport availability can have on community health and social wellbeing.

Keywords: access to services, health inequalities, transport and social exclusion.
\end{abstract}




\section{Introduction}

People's health varies by place of residence in New Zealand as elsewhere [1]. But where people live is shaped by factors such as employment opportunities, family history, and socio-economic circumstances. Internationally, the growing literature on the relationship between neighbourhoods and health suggests that the characteristics of places matter, as well as the characteristics of people, in determining differences in health outcomes between areas [2-5]. The mechanisms through which this occurs are still unclear but a number of pathways have been investigated, including variations between neighbourhoods in social capital [6]; sense of belonging to neighbourhood [7], features of the built urban environment [8]; access to food stores [9] and access to health related services and amenities [10].

Transport is a critical aspect of access to community resources and residents in lower socio-economic neighbourhoods are more likely to experience transport-related barriers to accessing non-local services and amenities than residents in higher socio-economic neighbourhoods. Poor geographic access is therefore likely to have a greater impact on health and well-being in lower socioeconomic neighbourhoods [11].

A systematic under-investment in community infrastructure in poor areas has been suggested as one explanation for neighbourhood variation in health [12]. However no consistent picture has emerged on the relationship between the socio-economic characteristics of urban localities and community resource access [13]. In some cities socio-economically poorer areas, or areas that are ethnically segregated, are relatively poorly endowed with community resources [14-17] but in other urban areas increasing deprivation has been associated with higher levels of community resource access [13, 18, 19]. A review of early studies by Lineberry [20, p. 186] indicated that "pockets of discrimination can be found, but probably not patterns of discrimination".

Health-related community resources include parks and recreational facilities which provide opportunities for physical exercise [21, 22], healthcare services, educational facilities, supermarkets and other stores that stock fruit, vegetables and other healthy foods [9], and community centres which provide venues for social interaction. Access to destinations such as public open space, shops or services within walking distance of home has been associated with increased levels of walking [23, 24] and reduced levels of obesity [8].

Equity of access to shops selling nutritious food has been investigated in several recent studies, and the term 'food deserts' has been coined to describe localities with poor access [25]. Studies in the USA have suggested that supermarket chains may be reducing facilities in poorer inner city areas creating food deserts and contributing to poorer diets [26, 27]. Evidence from UK research is mixed with some studies finding support for the food desert phenomena [25, 28, 29] and others not [30, 31].

A social gradient in geographic access to community resources can place lower socio economic households in a situation where they are disadvantaged in terms of walking or public transport access to services and amenities and limited 
financial resources to afford private transport. The potential for this situation to arise has particular saliency in New Zealand, a country with a small dispersed population, one of the highest rates of car ownership internationally and, in most areas, poor access to public transport [32, 33]. In 2002 New Zealand had 688 cars per thousand people, a rate exceeded only by USA, Portugal and Luxemburg. As an indication of public transport provision, in 1997/98 only $2.2 \%$ of households trip were made by bus and $.25 \%$ by rail [32]. New Zealand also has a relatively old vehicle fleet: a fifth of cars are less than seven years old and a sixth of cars are over sixteen years old [34]

While a high rate of car ownership may increase access to community resources for most of the population it is likely to exacerbate problems of access for the $10 \%$ of households that do not have access to a private vehicle [35]. As in other Western countries, the rise of car ownership in New Zealand has been paralleled by a decrease in walking and use of public transport. Associated changes have included sprawling low density suburban development and increased distances from home to daily destinations such as work, school and shopping facilities [36, 37]. Being carless in a car dependent environment can restrict access to health promoting opportunities and contribute to social isolation and exclusion [38, 39]. Concern over the social and environmental sustainability of dispersed, car dependent cities has contributed to a convergence of interests between the public health, urban design and transport sectors [32, 40].

The paper presents data on the relationship between geographic access to a range of health-related community resources and area level deprivation in New Zealand neighbourhoods. The findings of two studies are reported, one that was undertaken in the Auckland metropolitan area in 2002 [41] and a national study undertaken in 2005 [42]. Qualitative data will then be presented to provide some understanding of the potential health impacts of living in diverse socio-economic neighbourhoods with differing levels of access to community resources and forms of transport.

\section{Methodology}

Study 1: In 2002 geographical access to 36 different types of amenities and services was calculated using Geographical Information Systems (GIS) for 2,532 small areas (neighbourhoods) in Waitakere and North Shore cities in the Auckland metropolitan area. The amenities and services included in the study were identified by parents as important to their daily lives (e.g. supermarkets, fruit and vegetable shops, service stations, doctors, preschools, schools, libraries, parks, playgrounds, recreation centres). A Community Resources Accessibility Index (CRAI) was developed and used to calculate and map relative locational access to the 36 types of community resources at neighbourhood or meshblock level across the two cities (a meshblock is the smallest unit of dissemination of census data in New Zealand and the average number of people per meshblock in the study 1 area was 137). Network analysis which takes account of walkways as well as roads was used to calculate the travel distances between the centroids (the nominal centres) of the meshblocks and the nearest example of each type of 
facility or service. The centroid was used as a proxy for people's homes. A detailed account of the methodology is documented elsewhere [41].

The CRAI provides a composite score for access to the 36 types of services and amenities for each meshblock with each type of resource weighted in the index by the importance placed on access by parents of young children. By mapping the meshblock scores it is possible to identify neighbourhoods that are community resource rich and those that have poor overall access to services and amenities.

Study 2: In 2005 geographical access to 16 types of community resources was calculated using GIS for 38,350 small areas (neighbourhoods) across all of New Zealand. The 16 types of community resources were grouped into five domains: recreation amenities; shopping facilities; education facilities; health facilities and marae (a maori meeting place). A similar methodology was used as for study 1 with the key differences being: the use of population weighted centroids (the centre of population in the area rather then the geometric centroid) to accommodate the sparse and unevenly distributed populations in rural areas; the use of travel times instead of distances (adjusting for variations in speed limits, type of road surface and sinuosity); and access indices were calculated for each resource type rather than a composite index of overall accessibility. The methodology used to calculate accessibility in study 2 is also documented elsewhere [42].

For both studies data were obtained from national agencies, and central and local government organisations. Consistency and comparability of datasets was a primary concern. The precise location of each record was computed from its address using geocoding software.

Study 3: In 2005 seven focus groups were conducted in three urban and two rural centres around New Zealand to investigate the potential social and economic impacts of the introduction of a vehicle emission testing programme. Specific population groups were identified as vulnerable to the temporary or permanent loss of a vehicle if a testing programme was introduction: older people, families with children, low income households, Maori households, Pasifika households, people with disabilities and young people. Focus group participants were representatives of community and government agencies working with members of the identified population groups living in communities with varying levels of access to services, amenities and transport. A semi structured interview guide was used to stimulate conversation between participants.

\subsection{Analysis}

Using the access indices developed in studies 1 and 2 along with the $2001 \mathrm{New}$ Zealand Deprivation Index [43], an index based on nine socio-economic variables taken from the 2001 New Zealand Census, it has been possible to examine variation in access to community resources between neighbourhoods of differing levels of social deprivation. In addition study 2 has enabled the 
existence of a social gradient in community resource accessibility between rural and urban neighbourhoods to be investigated.

In study 1 standard regression analyses were undertaken to determine the extent to which meshblock deprivation and other population variables (residential turnover, ethnicity, families with children, population density and age) predicted meshblock level CRAI scores [13].

In study 2 chi-square tests were undertaken to establish whether observed differences in community resource accessibility between deprivation quintiles were significant for each facility type. Effect sizes were also examined as for large samples chi square can reach significance even for minimal differences.

An additional analysis examined whether the relationship between community resource accessibility and deprivation was dependent upon urban/rural status of the area. To undertake this analysis an urban, rural or intermediate rural/urban classification was given to all meshblocks using the New Zealand Urban-Rural Profile classification [44]. Median travel times to access the 16 types of community resources were calculated for deprivation quintiles in each urban/rural category. Significance was again tested using a chi-square analysis.

For study 3 focus group discussions were audio taped and the tapes were fully transcribed. Transcriptions of the interviews were loaded into QSR's NVivo software package then coded and analysed using thematic and discursive approaches.

\section{Results}

\subsection{Community resource access and deprivation}

Variation in geographic access to services and amenities was apparent in study 1 between the urban neighbourhoods of Waitakere and North Shore cities [41] and in study 2 differences were evident nationally between urban and rural areas, between neighbourhoods within urban areas, and between rural neighbourhoods [42]. For example, in study 2 travel time access to food stores between neighbourhoods in the city of Christchurch ranged from less than a minute in the central city to over 20 minutes in the semi-rural periphery.

In Waitakere and North Shore cities the current pattern of accessibility reflects the historical development of the cities with areas of better access generally located near the older economic centres and along the main access routes between them. Both cities have grown rapidly over the past sixty years as rural land has been developed between what were once isolated rural and coastal towns. Not surprisingly, study 2 results showed that nationally accessibility was generally better in urban and provincial centres than in rural areas.

With respect to neighbourhood deprivation, Study 1 findings indicated that community resource accessibility in Waitakere and North Shore cities was independently and positively associated with higher levels of deprivation. In both cities there was a gradual increase in accessibility from low deprivation to 
high deprivation meshblocks (Figure 1). However, overall levels of access were higher in North Shore, the wealthier of the two cities.

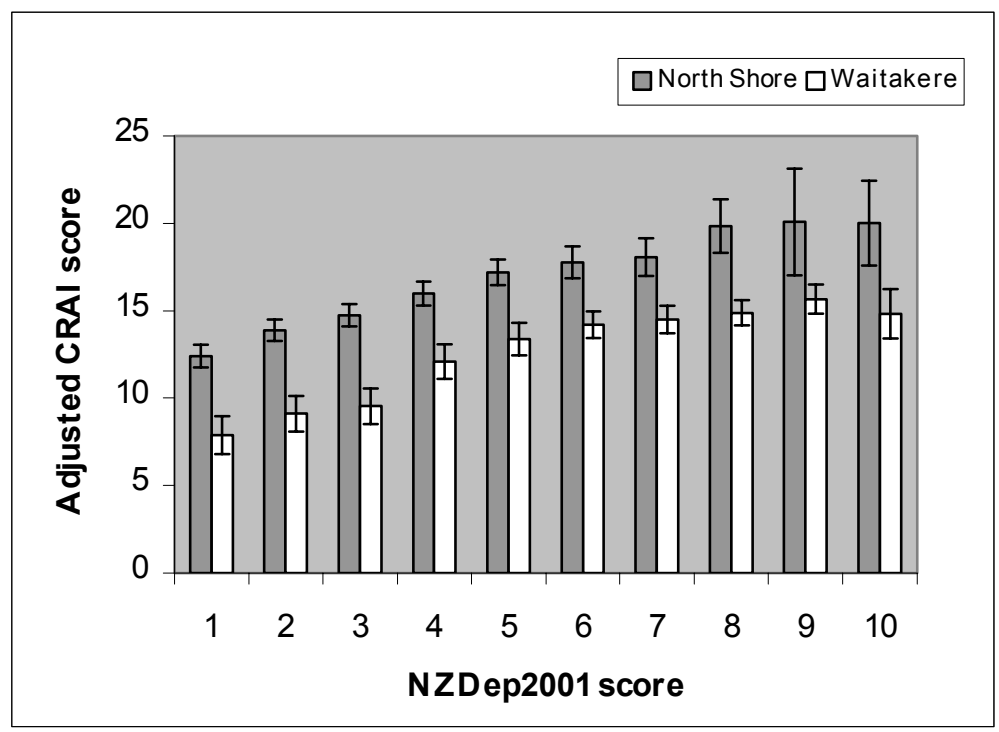

Figure 1: Community resource access by NZDep2001 in Waitakere and North Shore.

A social gradient in geographic access to community resource was also evident at the national level for 15 of the 16 community resources calculated in study 2. Median travel times were higher in the least deprived quintile (NZDep 2001 score) compared the most deprived quintile for all community resources other than beaches. In other words, with the exception of beaches access was significantly related to deprivation for all community resource sub-domains (Table 1 column a). The effect size was strongest for access to food shops, supermarkets, marae, primary schools and intermediate/full primary schools (in bold).

Table 1 column (b) indicates that a social gradient in travel time access to services and amenities was also evident when urban meshblocks were analysed independently. More deprived urban neighbourhoods generally had better access than less-deprived urban neighbourhoods to a range of services and amenities.

Although the findings of studies 1 and 2 indicate that areas of high deprivation tend to also be areas of high accessibility, there are pockets of locational disadvantage where high deprivation neighbourhoods (NZDep2001 scores of 9 or 10) have low accessibility (CRAI scores in the bottom $20 \%$ of the distribution) in study 1 and high travel times to specific sub-domains in study 2 . The residents in these neighbourhoods face a double jeopardy situation of poor access to personal resources as well as poor access to a range of community resources. 
Table 1: Relationship between deprivation and community resource accessibility for all New Zealand meshblocks and urban only meshblocks.

\begin{tabular}{|c|c|c|c|c|}
\hline & \multicolumn{2}{|c|}{$\begin{array}{l}\text { (a) Deprivation } \\
\text { New Zealand wide } \\
\mathrm{N}=38,350 \text { meshblocks }\end{array}$} & \multicolumn{2}{|c|}{$\begin{array}{l}\text { (b) Deprivation } \\
\text { Urban only } \\
\mathrm{N}=21,784 \text { meshblocks }\end{array}$} \\
\hline & Tau B & $\mathrm{P}$ value & Tau B & $P$ value \\
\hline \multicolumn{5}{|l|}{ Health } \\
\hline Accident and Emergency & -.130 & $<.001$ & -.174 & $<.001$ \\
\hline GP & -.192 & $<.001$ & -.156 & $<.001$ \\
\hline Pharmacy & -.192 & $<.001$ & -.162 & $<.001$ \\
\hline Plunket & -.116 & $<.001$ & -.088 & $<.001$ \\
\hline Ambulance Station & -.102 & $<.001$ & -.173 & $<.001$ \\
\hline Fire Station & -.085 & $<.001$ & -.111 & $<.001$ \\
\hline \multicolumn{5}{|l|}{ Diet } \\
\hline Food shops & -.245 & $<.001$ & -.231 & $<.001$ \\
\hline Supermarkets & -.211 & $<.001$ & -.184 & $<.001$ \\
\hline \multicolumn{5}{|l|}{ Recreation } \\
\hline Park & -.145 & $<.001$ & -.073 & $<.001$ \\
\hline Beach & .005 & .258 & .096 & $<.001$ \\
\hline Sports and leisure & -.171 & $<.001$ & -.160 & $<.001$ \\
\hline Marae & -.241 & $<.001$ & -.218 & $<.001$ \\
\hline \multicolumn{5}{|l|}{ Education } \\
\hline Kindy/day care & -.199 & $<.001$ & -.179 & $<.001$ \\
\hline Primary & -.226 & $<.001$ & -.184 & $<.001$ \\
\hline Intermediate/Full primary & -.228 & $<.001$ & -.188 & $<.001$ \\
\hline Secondary & -.198 & $<.001$ & -.172 & $<.001$ \\
\hline
\end{tabular}

With regard to the age and families variables in study 1, higher meshblock median age was positively associated with high accessibility, while the 'families with children' variable was negatively related to accessibility, both independently of other variables. The findings indicate young families were more likely to live in the periphery of the cities, where housing is more affordable, while older people were more likely to remain or move closer to service hubs in city and suburban centres.

\subsection{Health-related impacts of access and deprivation}

The results of the qualitative investigation, study 3, suggested that locality characteristics of access, topography and transport availability were critical to limiting the potential health impacts of increasing car ownership costs and/or the temporary or permanent loss of a private vehicle. Key findings will be discussed 
under the themes: car culture, transport choices and household budgets, vehicle safety and illegality, and social exclusion

\subsubsection{Car culture}

The car was portrayed as central to the New Zealand way of life. A driver's license can be acquired at age 15 and buying a car is a significant rite of passage. The importance of a vehicle was seen to go beyond its use as a mode of transport: it can be a form of entertainment and recreation, it can provide a sense of connection or inclusion in a community, as well as signifying freedom, prestige, choice and independence. For some households a car can be 'a roof over their head'. Health-related impacts were seen to vary between population groups: for new settlers a car can be a means of integrating into New Zealand society; for people with disabilities it was portrayed as providing access to a life; for youth vehicle ownership can be bound up with identity and autonomy; and for families with children it can be a safety net in times of emergency.

\subsubsection{Transport choices and household budgets}

Informants stressed that most New Zealand households, irrespective of income, placed higher priority on maintaining a car than most other items of household expenditure. In many areas public transport is non existent or an unviable option for accessing employment, medical and social services. While schools may be accessed on foot or by bus, a car is needed if children are to participate in weekend sports. In light of rising rates of childhood obesity barriers to exercise are a health issue. When participants were asked what low income households would cut back on to keep a car going the response was invariably 'food'. Informants from the housing sector noted that transience as a result of defaulting on rent payments could often be traced to vehicle related costs and fines. Housing, nutrition and physical activity are all key determinants of health (Acheson [39]).

\subsubsection{Vehicle safety and illegality}

While households placed priority on having a vehicle it was noted that for low income households' budgets frequently did not stretch to maintaining a registered and warranted vehicle. This would often lead to an accumulation of vehicle-related fines, contributing to financial hardship, and in some instances anti-police feeling and criminality. A drivers' license can not be obtained if the family car is not registered or warranted and informants indicated that this situation often resulted in families of illegal drivers. Potentially unsafe cars and unlicensed drivers on the road may compromise community safety.

\subsubsection{Social exclusion}

A lack of opportunity to participate in all forms of activity (occupational, educational recreational and social) and social isolation were identified as consequences of poor access to transport in many New Zealand neighbourhoods. The groups hardest hit were low income households, families with children, older people and people with disabilities. Being without a car was only seen to be a feasible option in the inner city suburbs of the larger cities where public 
transport and/or walking access to a range of facilities was adequate. Beyond these inner city precincts, public transport, particularly buses, was branded as 'down market' with comments made such as 'suits don't ride buses' and 'people think you're broke if you are on a bus'.

\section{Discussion}

Being without a car in a car dependent environment can make daily life difficult; a situation exacerbated when geographic access to services and amenities is poor and public transport is unavailable or sparse. Most New Zealand households choose to run a car and low income households make considerable sacrifices on other budget items to do so. A car provides a sense of security and control; it makes it possible to see and care for family and friends and to access essential services and amenities. The security, control and access a car provides may be health promoting but the study findings suggest that for some households these benefits are likely to be traded off against other health promoting commodities such as housing and food quality.

While mapping community resource access has indicated that there has been no systematic under investment in community infrastructure in poorer areas of New Zealand this does not detract from the difficulty experienced by households living without a car in pockets of low access, poor transport availability and limited personal means. Geographic access does not equate with effective access particularly in New Zealand's dispersed car dependent urban and rural neighbourhoods. Transport and accessibility have implications for a number of what are recognised to be wider determinants of health: employment, housing, nutrition, education, recreation and social interaction. And whereas walking and cycling are advocated as travel modes from health promotion and environmental sustainability perspectives, in the sprawling urban environments of Auckland the message can have a hollow ring. When a ten minute car journey from home to the closest supermarket equates to a 90 minute journey made up of walking segments and bus rides, the incentives for car ownership are obvious. Personal and household time budgets seldom allow for the distances that need to be traversed between destinations in most New Zealand neighbourhoods.

\section{Acknowledgements}

Study 1 was a component of The Place of Caregiving project funded by the Health Research Council of New Zealand (HRC) and undertaken in collaboration with Adrian Field and Daniel Exeter. Study 2 was a component of a Neighbourhoods and Health project funded by HRC and undertaken in collaboration with Jamie Pearce, Phil Bartie and Rosemary Hiscock. Study 3 was funded by the Ministry of Transport and undertaken on collaboration with Emily Rose and Tim McCreanor. 


\section{References}

[1] Blakely, T., Fawcett, J., Atkinson, J., et al., Decades of Disparity II: Socioeconomic Mortality Trends in New Zealand 1981-1999, Public Health Intelligence Occasional Bulletin Number 25. Ministry of Health: Wellington, 2005

[2] Macintyre, S., Maciver, S. \& Sooman, A., Area, class and health: should we be focusing on places or people? Journal of Social Policy, 22(2), pp. 213-234, 1993.

[3] Diez-Roux, A., Nieto, F., Muntaner, C., et al., Neighbourhood environments and coronary heart disease. American Journal of Epidemiology, 146(1), pp. 48-63, 1997.

[4] Pickett, K. \& Pearl, M., Multilevel analyses of neighbourhood socioeconomic context and health outcomes: a critical review. Journal of Epidemiology and Community Health, 55, pp. 111-122, 2001.

[5] Kawachi, I. \& Berkman, L., (eds). Neighbourhoods and Health, Oxford University Press: Oxford, 2003.

[6] Baum, F. \& Palmer, C., 'Opportunity structure': urban landscape, social capital and health promotion in Australia. Health Promotion International, 17, pp. 351-361, 2002.

[7] Young, A., Russell, A. \& Powers, J., The sense of belonging to a neighbourhood: can it be measured and is it related to health and well being in older women? Social Science and Medicine, 59, pp. 2627-2637, 2004.

[8] Ellaway, A., Macintyre, S. \& Bonnefoy, X., Graffiti, greenery, and obesity in adults: secondary analysis of European cross sectional survey. BMJ, doi:10.1136/bmj.38575.664549.F7 (published 19 August 2005), 2005.

[9] Cummins, S. \& Macintyre, S., A systematic study of an urban foodscape: the price and availability of food in greater Glasgow. Urban Studies, 39(11), pp. 2115-2130, 2002.

[10] Altschuler, A., Somkin, C. \& Adler, N., Local services and amenities, neighbourhood social capital, and health. Social Science and Medicine, 59, pp. 1219-1229, 2004.

[11] Talen, E., Visualizing fairness: Equity maps for planners. Journal of the American Planning Association, 64(1), pp. 22-38, 1998.

[12] Lynch, J., Income inequality and health: expanding the debate. Social Science and Medicine, 51, pp. 1001-1005, 2000.

[13] Field, A., Witten, K., Robinson, E., et al., Who gets to what? Access to community resources in two New Zealand cities. Urban Policy and Research, 22, pp. 189-205, 2004.

[14] Badcock, B., Unfairly Structured Cities. 1984, Basil Blackwell: Oxford, 1984.

[15] Pacione, M., Access to urban services - the case of secondary schools in Glasgow. Scottish Geographical Magazine, 105(1), pp. 12-18, 1989. 
[16] Sooman, A. \& Macintyre, S., Health and perceptions of the local environment in socially contrasting neighbourhoods in Glasgow. Health and Place, 1(1), pp. 15-26, 1995.

[17] Williams, D.R. \& Collins, C., Racial residential segregation: A fundamental cause of racial disparities in health (Viewpoint). Public Health Reports, 116(5), pp. 404-416, 2001.

[18] McLafferty, S., Urban structure and geographical access to public services. Annals of the Association of American Geographers, 72(3), pp. 347-354, 1982.

[19] Mladenka, K.R., Organizational rules, service equality and distributional decisions in urban politics. Social Science Quarterly, 59(1), pp. 192-201, 1978.

[20] Lineberry, R.L., Equality and Urban Policy: The Distribution of Municipal Public Services. 1977, Sage: Beverly Hills, 1977.

[21] Humpel, N., Owen, N., Iverson, D., et al., Perceived environment attributes, residential location, and walking for particular purposes. American Journal of Preventive Medicine, 26(2), pp. 119-125, 2004.

[22] Giles-Corti, B. \& Donovan, R.J., The relative influence of individual, social and physical environment determinants of physical activity. Social Science \& Medicine, 54, pp. 1793-1812, 2002.

[23] Carnegie, M., Bauman, A., Marshall, A., et al., Perceptions of the physical environment, stage of change for physical activity, and walking among Australian adults. Research Quarterly for Exercise and Sport, 73(2), pp. 146-156, 2002.

[24] Giles-Corti, B. \& Donovan, R., Relative influences of individual, social environmental, and physical environmental correlates of walking. American Journal of Public Health, 93(9), pp. 1583-1589, 2003.

[25] Clarke, G., Eyre, H. \& Guy, C., Deriving indicators of access to food retail provision in British cities: Studies of Cardiff, Leeds and Bradford. Urban Studies, 39, pp. 2041-2060, 2002.

[26] Morland, K., Wing, S. \& Diez Roux, A., Neighborhood characteristics associated with the location of food stores and food service places. American Journal of Preventive Medicine, 22, pp. 23-29, 2002.

[27] Alwitt, L. \& Donley, T., Retail stores in poor urban neighborhoods. Journal of Consumer Affairs, 31, pp. 139-164, 1997.

[28] Ellaway, A. \& Macintyre, S., Women in their place: gender and perceptions of neighbourhoods and health in the West of Scotland. Geographies of Women's Health : Place, Diversity and Difference, Dyck, I., Lewis, N., and McLafferty, S., eds., Routledge: London, pp., 2000.

[29] Whelan, A., Wrigley, N., Warm, D., et al., Life in a 'food desert'. Urban Studies, 39(11), pp. 2083-2100, 2002.

[30] Cummins, S. \& Macintyre, S., "Food deserts" - evidence and assumption in health policy making. BMJ, 325(7361), pp. 436-439, 2002.

[31] Cummins, S., Macintyre, S., Davidson, S., et al., Measuring neighbourhood social and material context: generation and interpretation 
of ecological data from routine and non-routine sources. Health Place, 11, pp. 249-260, 2005.

[32] Ministry of Transport, New Zealand Transport Strategy, Wellington, 2002 $<$ http://www.beehive.govt.nz/nzts/docs/nzts_v13_23nov02.pdf $>$.

[33] Organization for Economic Co-operation and Development, OECD Factbook, OECD: Paris, 2005

[34] Emigration New Zealand, Interesting Facts About New Zealand, http://www.emigratenz.org/.

[35] Statistics New Zealand, 2001 Census of Population and Dwellings: Families and Households, Wellington, 2002 $<$ http://www.stats.govt.nz/NR/rdonlyres/ED8AF5A8-9FA8-4865-BD828ADA357DE7E3/0/FamiliesandHouseholds.pdf $>$.

[36] Newman, P., Walking in a historical, international and contemporary context. Sustainable Transport: Planning for Walking and Cycling in Urban Environments, Tolley, R., ed. Woodhead Publishing: Cambridge, pp. 48-58, 2003.

[37] Social Exclusion Unit, Making the Connections Final Report on Transport and Social Exclusion, Social Exclusion Unit, Office of the Deputy Prime Minister: London, 2003

[38] Bostock, L., Pathways of disadvantage? Walking as a mode of transport among low-income mothers. Health and Social Care in the Community, 9(1), pp. 11-18, 2001.

[39] Acheson, D., Independent Inquiry into Inequalities in Health, Stationary Office: London, 1998

[40] Ministry for the Environment, New Zealand Urban Design Protocol, Wellington, 2005

[41] Witten, K., Exeter, D. \& Field, A., The quality of urban environments: Mapping variation in access to community resources. Urban Studies, 40(1), pp. 161-177, 2003.

[42] Pearce, J., Witten, K. \& Bartie, P., Neighbourhoods and health: a GIS approach to measuring community resource accessibility. Journal of Epidemiology and Community Health, in press, 2006.

[43] Salmond, C. \& Crampton, P., NZDep2001 Index of Deprivation, Department of Public Health, Wellington School of Medicine: Wellington, 2002

[44] Statistics New Zealand, Defining Urban and Rural New Zealand, http:/www.stats.govt.nz/urban-rural-profiles/defining-urban-ruralnz/default.htm. 